\title{
A Lista de Fauna Ameaçada de Extinção e os Entraves para a Inclusão de Espécies - o Exemplo dos Peixes Troglóbios Brasileiros
}

\author{
The List of Endangered Fauna and Impediments to Inclusion of Species - \\ the Example of Brazilian Troglobitic Fish
}

Jonas Eduardo Gallão* \& Maria Elina Bichuette

Laboratório de Estudos Subterrâneos, Departamento de Ecologia e Biologia Evolutiva,

Universidade Federal de São Carlos - UFSCar, São Carlos, SP, Brasil

\section{O Meio Subterrâneo - Definição e Organismos}

O meio subterrâneo ou hipógeo compreende os espaços interconectados do subsolo, com dimensões variáveis, desde milímetros a grandes dimensões (cavernas), que foram formados em rocha maciça e estão preenchidos por água ou ar (Juberthie 2000).

Quando comparado ao meio epígeo (superfície), o ambiente subterrâneo apresenta algumas particularidades: ausência permanente de luz nas zonas profundas, acarretando a exclusão de organismos fotossintetizantes, o que geralmente resulta em condições de escassez alimentar e dependência de itens alóctones; tendência à estabilidade térmica e elevada umidade relativa do ar, aproximando-se da saturação. Estas últimas relacionadas ao efeito tampão da rocha circundante (Culver 1982).

Essas condições particulares resultam em um regime seletivo diferenciado, portanto, somente espécies epígeas que possuem estados de caráter que podem ser úteis em um novo modo de vida teriam maior probabilidade de estabelecer populações no meio hipógeo. Dentre estes, algumas modalidades sensoriais podem ser consideradas: orientação não dependente de visão, como quimio- e mecanorrecepção; dieta generalista e/ou detritívora (Culver 1982).

Organismos regularmente encontrados em ambientes subterrâneos são classificados considerando-se suas histórias ecológico-evolutivas. Assim, a classificação proposta por Schiner-Racovitza (1907) considera a ocorrência ou não no

\footnotetext{
*Autor para correspondência: Jonas Eduardo Gallão

Departamento de Ecologia e Biologia Evolutiva, Universidade Federal de São Carlos - UFSCar, CP 676, CEP 13565-905, São Carlos, SP, Brasil

E-mail: jonasgallao@yahoo.com.br
}

meio superficial e presença/ausência de estados de caráter relacionados ao isolamento no meio hipógeo, dividindo-os em: trogloxenos - habitam o meio hipógeo regularmente, no entanto, devem retornar periodicamente à superfície para completarem seu ciclo de vida; troglófilos - capazes de colonizar efetivamente tanto o meio hipógeo quanto o epígeo, são os cavernícolas facultativos; troglóbios - restritos ao meio subterrâneo, incapazes de estabelecer populações epígeas. Todavia, em uma proposta de classificação mais recente, Trajano (2012) considera os trogloxenos populações fonte no meio epígeo, as quais utilizam recursos subterrâneos; troglófilos populações fonte tanto em meio hipógeo quanto epígeo e troglóbios populações fonte exclusivamente subterrâneas. Para o Brasil, encontramos peixes troglóbios e troglófilos. Peixes trogloxenos ocorrem somente em outros países como os Estados Unidos (Trajano \& Bichuette 2010a).

Dentre as especializações mais marcantes, estão a redução e até ausência de pigmentação melânica cutânea e olhos, chamados de troglomorfismos característicos. Troglóbios são inerentemente frágeis e vulneráveis a alterações ambientais, apresentando populações frequentemente pequenas e com baixa resiliência, assim, todas as espécies deveriam ser protegidas por lei e ao menos estar presente na categoria vulnerável (VU) da IUCN (International Union for Conservation of Nature). Ainda, a intensa exploração de bens minerais no país cresceu enormemente nos últimos quatro anos após a publicação de um Decreto (número 6640) que categoriza cavidades naturais subterrâneas em níveis de relevância. Apenas aquelas de relevância máxima são efetivamente protegidas. Tal fato tem levado à supressão de maciços inteiros, sejam em rocha calcária e/ ou outras litologias (é o caso de minério de ferro) e levado à perda da biodiversidade subterrânea (Trajano \& Bichuette 
2010b). Além disso, de acordo com a nova legislação que regulamenta o uso de cavernas para fins econômicos e consequente total supressão, um dos critérios que denota relevância máxima e total proteção do meio subterrâneo é a presença de espécies em risco de extinção, constantes de listas oficiais. Deste modo, é de extrema relevância a inclusão de troglóbios em listas de fauna ameaçada.

\section{Peixes Troglóbios Brasileiros e a Inserção de Espécies no Livro Vermelho}

Atualmente são conhecidas 166 espécies válidas de peixes troglóbias no mundo (Proudlove 2010) e o Brasil desponta com registro de 25 espécies (19 válidas e seis não descritas formalmente), a maioria incluída em listas de fauna ameaçada (Trajano \& Bichuette 2010a) (Tabela 1). Na atual revisão da Lista, já homologada em 2011 pelo Instituto Chico Mendes para Conservação da Biodiversidade (ICMBio), foram adicionadas nove espécies, além das cinco propostas em 2005 (Machado et al. 2008). Note-se que, além de algumas espécies ainda não descritas, Pimelodella spelaea, Rhamdia enfurnada e Phreatobius dracunculus também não foram avaliadas na última oficina da IUCN, entretanto, estas serão consideradas em oficinas de avaliação futuras.

Segundo Rosumek \& Martins (2010), o tempo e o dinheiro destinados à conservação sempre serão escassos e por muitas vezes insuficientes, o que impossibilita a proteção de todas as espécies do planeta. Deste modo, há a alternativa de escolhermos áreas prioritárias para a conservação da biodiversidade. Um critério para a escolha de áreas com propósitos de conservação de espécies é o grau de endemismo (Prevedello \& Carvalho 2006; Carvalho 2009). Ainda, há a lista da IUCN, baseada em graus de ameaças, que no Brasil é compilada na forma do Livro Vermelho da Fauna Brasileira Ameaçada de Extinção. A primeira versão da lista foi publicada em 1968 e apenas em 1989 e 2005 esta foi revisada (Machado et al. 2008), o que causou um grande déficit de informações sobre as ameaças à nossa fauna. No momento, a quarta revisão, a qual é organizada pelo ICMBio, está em andamento, com alguns grupos já contemplados e um adendo especial para a fauna troglóbia brasileira.

As categorias utilizadas pela IUCN são: Extinto (EX - não há sobreviventes da espécie); Extinto na Natureza (EW - o táxon existe somente em cativeiro); Criticamente em Perigo (CR - risco extremamente alto de extinção na natureza em curto prazo); Em Perigo (EN - risco alto de extinção na natureza em curto prazo); Vulnerável (VU - risco alto de extinção na natureza em médio prazo); Quase Ameaçada (NT - não atinge um critério de ameaça, mas se aproxima de VU); Não Ameaçada (LC - não apresenta risco de extinção) e Deficiente em Dados (DD - não há dados suficientes para detecção de graus de ameaça) (Machado et al. 2008). Fitter \& Fitter (1987) discutem alguns entraves para inclusão de espécies em listas de fauna ameaçada e consideram: 1 - as espécies listadas devem ser estudadas para determinação de densidades demográficas e seus números populacionais;
2 - os estudos devem abranger toda área de ocorrência da espécie; 3 - as categorias não são adequadas para muitos táxons, como insetos, dos quais pouco se sabe da biologia e taxonomia; 4 - espécies que não são mais encontradas permanecem na categoria deficiente em dados e deveriam ser listadas como extintas na natureza ou em algum critério de ameaça.

Para uma efetiva e eficiente compilação da lista nacional, é fundamental que todos os estados elaborem, antecipadamente, suas listas regionais. A iniciativa deve partir dos órgãos ambientais de cada estado, chamando as sociedades científicas pertinentes ao tema para eficaz e criteriosa participação. Entretanto, para a revisão de 2005, somente os estados do Paraná, Minas Gerais, São Paulo, Rio de Janeiro, Rio Grande do Sul, Espírito Santo e Pará apresentaram lista própria (Machado et al. 2008).

Outro ponto problemático é a demora nos intervalos entre as revisões, comumente engessando espécies em categorias mais brandas ou mesmo deixando outras em categorias de maior ameaça. Para evitar que isto ocorra, a publicação de suplementos à lista possibilitaria um maior dinamismo, não necessariamente inflacionando esta, já que espécies podem tanto entrar na lista, sair ou apenas mudar de categoria. Como exemplo, podemos considerar o lambari Stygichthys typhlops, espécie troglomórfica que vive em lençol freático na bacia do Médio rio São Francisco, município de Jaíba, norte de Minas Gerais (Moreira et al. 2010). O córrego Escuro, afloramento superficial do lençol, era perene até meados de 1980 e hoje é um riacho intermitente com drenagem superficial apenas no pico da estação chuvosa, assim, é inevitável atribuir esse rebaixamento acelerado ao intenso bombeamento de água subterrânea, principalmente para projetos de irrigação (Silva 1984) - a região é semiárida e umas das maiores produtoras de banana do mundo. Outra ameaça em potencial é a contaminação do lençol freático por defensivos agrícolas, devido à intensa atividade agrícola (Moreira et al. 2010). Apesar disso, a espécie foi incluída apenas como VU na lista de 2005. Somente na atual revisão, em 2011, sua categoria foi elevada para EN (Tabela 1). Assim como o S. typhlops, as espécies Phreatobius cisternarum e P. dracunculus também estão distribuídas em aquíferos subterrâneos extensos. Para estas duas últimas espécies é necessária uma delimitação de área mínima de proteção. Apenas estudos populacionais possibilitarão esta delimitação e estes devem ser financiados por órgãos de fomento.

A presença das espécies nas listas de fauna ameaçada é eficaz na proteção do local em que estas ocorrem, no entanto, e principalmente no caso específico de cavernas, o entorno também deve estar na área de proteção (Culver 1982). Por exemplo, as sete espécies de peixes troglóbios que ocorrem em São Domingos-GO, estão localizadas em cavernas nos limites do Parque Estadual de Terra Ronca (PETER), estando teoricamente protegidas. Entretanto, todas as nascentes dos rios que atravessam as cavernas do PETER ficam fora da área do parque. Aquela região é conhecida pela criação extensiva de gado e plantio de monoculturas, 
Tabela 1. Peixes troglóbios do Brasil com respectivas localidades e categorias IUCN.

\begin{tabular}{|c|c|c|c|c|c|c|}
\hline Espécie & Município & $\begin{array}{l}\text { Categoria } \\
2005\end{array}$ & $\begin{array}{l}\text { Revisão } \\
2011\end{array}$ & AC & MT & $\mathbf{N}$ \\
\hline Stygichthys typhlops Brittan \& Böhlke 1965 & Jaíba-MG & VU & EN & 1962 & & \\
\hline Eigenmannia vicentespelaea Triques 1996 & São Domingos-GO & VU & VU & 1978 & & \\
\hline Ancistrus cryptophthalmus Reis 1987 & São Domingos-GO & $\begin{array}{l}\text { Não } \\
\text { constava }\end{array}$ & EN & 1972 & & \\
\hline Ancistrus formoso Sabino \& Trajano 1997 & Bonito-MS & VU & VU & 1995 & & \\
\hline $\begin{array}{l}\text { Trichomycterus itacarambiensis Trajano \& de } \\
\text { Pinna } 1996\end{array}$ & Itacarambi-MG & VU & CR & 1986 & & \\
\hline $\begin{array}{l}\text { Trichomycterus dali Rizzato, Costa Jr., } \\
\text { Trajano \& Bichuette } 2011\end{array}$ & Bonito-MS & $\begin{array}{l}\text { Não } \\
\text { constava }\end{array}$ & VU & 1998 & & \\
\hline Trichomycterus sp. 1 & Carinhanha-BA & $\begin{array}{l}\text { Não } \\
\text { constava }\end{array}$ & $\begin{array}{c}\text { Não } \\
\text { avaliada }\end{array}$ & 1999 & $\begin{array}{l}\text { LES- } \\
\text { UFSCar, } \\
\text { ds }\end{array}$ & 8 \\
\hline Trichomycterus sp. 2 & Carinhanha-BA & - & $\begin{array}{l}\text { Não } \\
\text { avaliada }\end{array}$ & 2011 & $\begin{array}{l}\text { LES- } \\
\text { UFSCar }\end{array}$ & 5 \\
\hline Ituglanis mambai Bichuette \& Trajano 2008 & Posse-GO & $\begin{array}{l}\text { Não } \\
\text { constava }\end{array}$ & $\mathrm{LC}$ & 2004 & & \\
\hline Ituglanis bambui Bichuette \& Trajano 2004 & São Domingos-GO & $\begin{array}{l}\text { Não } \\
\text { constava }\end{array}$ & EN & 1999 & & \\
\hline Ituglanis epikarsticus Bichuette \& Trajano 2004 & São Domingos-GO & $\begin{array}{l}\text { Não } \\
\text { constava }\end{array}$ & VU & 1978 & & \\
\hline Ituglanis ramiroi Bichuette \& Trajano 2004 & São Domingos-GO & $\begin{array}{l}\text { Não } \\
\text { constava }\end{array}$ & VU & 1999 & & \\
\hline Ituglanis passensis Fernandez \& Bichuette 2002 & São Domingos-GO & $\begin{array}{l}\text { Não } \\
\text { constava }\end{array}$ & VU & 1978 & & \\
\hline $\begin{array}{l}\text { Glaphyropoma spinosum Bichuette, } \\
\text { de Pinna \& Trajano } 2008\end{array}$ & Andaraí-BA & - & VU & 2006 & & \\
\hline Copionodon sp. & Andaraí-BA & - & $\begin{array}{c}\text { Não } \\
\text { avaliada }\end{array}$ & 2006 & $\begin{array}{l}\text { LES- } \\
\text { UFSCar }\end{array}$ & 30 \\
\hline Pimelodella kronei (Ribeiro 1907) & Alto Ribeiro-SP & VU & $\mathrm{EN}$ & $1905^{\beta}$ & & \\
\hline Pimelodella spelaea Trajano, Reis \& Bichuette 2004 & São Domingos-GO & $\begin{array}{c}\text { Não } \\
\text { constava }\end{array}$ & $\begin{array}{c}\text { Não } \\
\text { avaliada }\end{array}$ & 1999 & & \\
\hline Rhamdia enfurnada Bichuette \& Trajano 2005 & Carinhanha-BA & $\begin{array}{l}\text { Não } \\
\text { constava }\end{array}$ & $\begin{array}{c}\text { Não } \\
\text { avaliada }\end{array}$ & 2003 & & \\
\hline Rhamdia sp. & Serra da Bodoquena-MS & $\begin{array}{l}\text { Não } \\
\text { constava }\end{array}$ & $\begin{array}{c}\text { Não } \\
\text { avaliada }\end{array}$ & 2004 & $\begin{array}{l}\text { DZ- } \\
\text { IBUSP }\end{array}$ & 15 \\
\hline Rhamdiopsis krugi Bockmann \& Castro 2010 & Itaetê-BA & $\begin{array}{l}\text { Não } \\
\text { constava }\end{array}$ & VU & 1991 & & \\
\hline Rhamdiopsis sp. 1 & Cordisburgo-MG & $\begin{array}{l}\text { Não } \\
\text { constava }\end{array}$ & $\begin{array}{l}\text { Não } \\
\text { avaliada }\end{array}$ & 2003 & LIRP & 10 \\
\hline Rhamdiopsis sp. 2 & Campo Formoso-BA & $\begin{array}{l}\text { Não } \\
\text { constava }\end{array}$ & CR & 1997 & LIRP, ds & 7 \\
\hline Phreatobius cisternarum Goeldi 1905 & $\begin{array}{l}\text { Delta do Amazonas-AM/ } \\
\text { PA }\end{array}$ & $\begin{array}{l}\text { Não } \\
\text { constava }\end{array}$ & $\mathrm{LC}$ & $1904^{\beta}$ & & \\
\hline $\begin{array}{l}\text { Phreatobius dracunculus Shibatta, Muriel-Cunha \& } \\
\text { de Pinna } 2007\end{array}$ & Rio Pardo-RO & - & $\begin{array}{c}\text { Não } \\
\text { avaliada }\end{array}$ & 2005 & & \\
\hline Aspidoras aff. albater Nijssen \& Isbrücker 1976 & Posse-GO & - & $\begin{array}{c}\text { Não } \\
\text { avaliada }\end{array}$ & $2006^{*}$ & & \\
\hline
\end{tabular}

VU - Vulnerável, EN - Em Perigo, CR - Criticamente em perigo, LC - Não Ameaçada. AC - Ano de coleta do material; MT - material testemunho para epécies não descritas; $\mathrm{N}$ - número de exemplares. LES - Laboratório de Estudos Subterrâneos (Dra. Maria Elina Bichuette); DZ-IBUSP - Departamento de Zoologia, Instituto de Biociências (Dra. Eleonora Trajano); LIRP - Laboratório de Ictiologia de Ribeirão Preto (Dr. Flávio Alcino Bockmann). ds - descrição submetida. *Ano de descoberta da população subterrânea. ${ }^{\beta}$ - Possível ano de coleta das espécies. 
assoreando e poluindo os rios e prejudicando o habitat $\mathrm{e}$ aporte de material alóctone para as cavernas (Bichuette \& Trajano 2010). A despeito disso, somente uma espécie troglóbia constava na lista de fauna ameaçada, e, na revisão de 2011, outras cinco espécies foram incluídas (Tabela 1).

Há também o exemplo do bagre cego de Iporanga, Pimelodella kronei, que habita cavernas do Parque Estadual Turístico do Alto Ribeira (PETAR), sul do estado de São Paulo, e seu hábitat sofre poluição por organoclorados há décadas (Bichuette \& Trajano 2010). Em 1989 e 2005 esta espécie encontrava-se na categoria vulnerável e, atualmente foi elevada para EN, refletindo a dificuldade de inclusão em categorias que realmente retratam o grau de ameaça. Apesar da revisão em 2005 ter sido realizada por especialistas, esta não foi feita por estudiosos da espécie, e aspectos de sua biologia e ecologia foram negligenciados, pois se tratavam de observações diretas em campo, sem publicação em periódicos para consulta. Sendo assim, as revisões devem abranger um número maior de especialistas, o que já vem sendo feito nas consultas amplas.

As falhas listadas até o momento não são facilmente sanáveis, entretanto, para a inclusão de espécies nas listas há um problema maior. A rígida burocracia ambiental aceita a inclusão apenas de espécies nominais. Uma alternativa é o incentivo e finaciamento de amplos projetos para inventariamento (a exemplo do All Catfish Species Inventory, financiado pela National Scientific Foundation, EUA), além de monitoramento de populações ameaçadas, para fins de descrição e proteção efetiva da nossa biodiversidade. Desta maneira, o investimento em pesquisa básica é urgente. Ainda, temos a questão do que é chamado na literatura como Wallacean and Linnean shortfalls, que preconiza que o conhecimento da biodiversidade é inadequado pois muitas espécies permanecem sem estudos formais no que concerne a sistemática e biogeografia (Bini et al. 2006), além das variações geográficas.

Para o impedimento taxonômico, temos o caso do bagrinho Rhamdiopsis krugi, conhecido desde o início da década de 1990 e não avaliado em listas de fauna ameaçada anteriores, embora as ameaças ao seu habitat fossem evidentes. Sua inclusão foi feita na revisão de 2011, após a descrição formal feita por Bockmann \& Castro (2010). Nesta mesma revisão uma exceção foi concedida a outra espécie de Rhamdiopsis de cavernas do semiárido da Bahia, sendo incluída na categoria CR. A pressão dos coordenadores de táxon foi fundamental para sua inclusão mesmo sem descrição formal, já que foi demonstrada a presença de caracteres diagnósticos, suficiente para validar sua inclusão.

Segundo Vanzolini (1992) e Marques \& Lama (2006), o número de sistematas no Brasil está aquém do necessário, sendo que cerca de $7 \%$ das espécies da fauna descritas para o mundo ocorrem no Brasil. Se considerarmos o potencial para novas descobertas, a falta de especialistas é ainda mais dramática nos dias de hoje. Como consequência, há um enorme déficit de especialistas capacitados e com tempo hábil para descrever espécies, representando um dos principais entraves à conservação destas. No caso dos peixes troglóbios, cinco espécies não puderam ser avaliadas na revisão de 2011, pois não foram descritas formalmente ainda, ou seja, não há nenhum modo legal de proteção das mesmas, principalmente as duas espécies de peixes troglóbios de Carinhanha, no sudoeste da Bahia, onde a pressão pela mineração de calcário é alta e a expansão agrícola avança em ritmo acelerado.

Como a avaliação de espécies é feita sob a alcunha de um nome científico, as variações geográficas são analisadas como um todo, preterindo muitas vezes uma população ameaçada em detrimento daquelas que apresentam pequeno risco de ameaça. Aqui, temos como exemplo o bagrinho Aspidoras albater, peixe bastante comum na bacia do rio Tocantins. Entretanto, de acordo com Secutti et al. (2011) há populações cavernícolas na região de Posse, nordeste de Goiás, já em processo de diferenciação, apresentando troglomorfismos e ocorrendo em localidades onde o entorno da caverna apresenta-se completamente desmatado. Contudo na revisão de 2011 esta espécie não foi considerada ameaçada, já que não se considerou aspectos da variação geográfica. Aqui temos uma clara referência ao Wallacean shortfall, o qual preconiza que, para a maioria dos táxons, as distribuições geográficas não são claramente compreendidas e atualmente apresentam muitas lacunas (Bini et al. 2006). Deste modo, tornam-se necessários mais estudos de cunho ecológico-evolutivos.

Propomos aqui algumas discussões a serem consideradas nos processos de avaliação de espécies ameaçadas:

- financiamento de estudos mais acurados e abrangentes, ainda, estudos com foco na fauna cavernícola;

- as revisões das listas devem ocorrer em intervalos periódicos, e caso uma espécie sofra forte pressão e necessite de rápida mudança de categoria de ameaça, suplementos à Lista podem ser publicados, desta forma, não inflacionando a compilação nacional. Da mesma forma, muitas espécies devem sair da Lista, caso as proposta de conservação dos especialistas sejam realizadas

- os limites espaciais de proteção das espécies, além de englobar o hábitat, devem também incluir as bacias hidrográficas nas quais estas se incluem, visto que grande parte do alimento presente no meio subterrâneo é de origem alóctone; e

- deve-se flexibilizar a inclusão de espécies sem descrição formal, mas que apresentam diagnoses inequívocas e tenham exemplares testemunho depositados em coleções científicas.

\section{Agradecimentos}

À Eleonora Trajano (IBUSP/SP) por disponibilizar informações ainda não publicadas formalmente e aos dois revisores anônimos pelos comentários construtivos; à Fundação de Amparo à Pesquisa do Estado de São Paulo (FAPESP, processos 2008/05678-7 e 2010/08459-4). J. E. 
Gallão agradece à Coordenação de Aperfeiçoamento de Pessoal de Nível Superior (Capes) pela bolsa de Mestrado concedida e ao Programa de Pós-Graduação em Ecologia e Recursos Naturais (PPGERN) pelo suporte para o desenvolvimento do presente.

\section{Referências}

Bini LM et al., 2006. Challenging Wallacean and Linnean shortfalls: knowledge gradients and conservation planning in a biodiversity hotspot. Diversity and Distributions, 12:475482. http://dx.doi.org/10.1111/j.1366-9516.2006.00286.x

Bockmann FA \& Castro RMC, 2010. The blind catfish from the caves of Chapada Diamantina, State of Bahia, northeastern Brazil (Siluriformes: Heptapteridae): description, anatomy, phylogenetic relationships, natural history, and biogeography. Neotropical Ichthyology, 8(4):673-706.

Bichuette ME \& Trajano E, 2010. Conservation of Subterranean Fishes. In: Trajano E, Bichuette ME \& Kapoor BG (eds.). Biology of Subterranean Fishes. New Hampshire: Science Publishers. p. 65-80. http://dx.doi.org/10.1201/ EBK1578086702-c3

Carvalho CJB, 2009. Padrões e endemismos e a conservação da biodiversidade. Megadiversidade, 5(1-2):77-86.

Culver DC, 1982. Cave Life - Evolution and Ecology. Cambridge: Harvard University Press.

Fitter RSR \& Fitter M, 1987. The road to extinction: problems of categorizing the status of taxa threatened with extinction. Gland: IUCN.

Juberthie C, 2000. The diversity of the karstic and pseudokarstic hypogean habitats in the world. In: Wilkens $\mathrm{H}$, Culver DC \& Humphreys WF (eds.). Ecosystems of the World, Vol. 30: Subterranean Ecosystems. Amsterdam: Elsevier. p. 17-39.

Machado ABM, Drummond GM \& Paglia AP, 2008. Livro vermelho da fauna brasileira ameaçada de extinção. Brasília: Fundação Biodivesitas, Ministério do Meio Ambiente.
Moreira CR et al., 2010. Rediscovery and redescription of the unusual subterranean characiform Stygichthys typhlops, with notes on its life history. Journal of Fish Biology, 76:1815-1824. PMid:20557633. http://dx.doi. org/10.1111/j.1095-8649.2010.02625.x

Prevedello JA \& Carvalho CJB, 2006. Conservação do Cerrado brasileiro: o método pan-biogeográfico como ferramenta para a seleção de áreas prioritárias. Natureza e Conservação, 4:39-57.

Proudlove GS, 2010. Biodiversity and distribution of the subterranean fishes of the world. In Trajano E, Bichuette ME \& Kapoor BG (eds.). Biology of Subterranean Fishes. New Hampshire: Science Publishers. p. 41-63. http://dx.doi. org/10.1201/EBK1578086702-c2

Rosumek FB \& Martins RP, 2010. Ecologia, Filosofia e Conservação. Natureza e Conservação, 8(1):87-89.

Secutti S, Reis R \& Trajano E, 2011. Differentiating cave Aspidoras catfish from a karst area of Central Brazil, upper rio Tocantins basin (Siluriformes: Callichthyidae). Neotropical Ichthyology, 9(4):689-695. http://dx.doi.org/10.1590/ S1679-62252011005000045

Trajano E, 2012. Ecological classification of subterranean organisms. In: White WB \& Culver DC (eds.). Encyclopedia of Caves. Amsterdam: Elsevier. p. 275-277. http://dx.doi. org/10.1016/B978-0-12-383832-2.00035-9

Trajano E \& Bichuette ME, 2010a. Subterranean Fishes of Brazil. In: Trajano, E, Bichuette ME \& Kapoor BG (eds.). Biology of Subterranean Fishes. New Hampshire: Science Publishers. p. 331-355. http://dx.doi.org/10.1201/EBK1578086702-c9

Trajano E \& Bichuette ME, 2010b. Relevância de cavernas: porque estudos ambientais espeleobiológicos não funcionam. Espeleo-Tema, 21(1):105-112.

Vanzolini PE, 1992. Paleoclimas e especiação em animais da América do Sul tropical. Estudos Avançados, 6(15):41-65. http://dx.doi.org/10.1590/S0103-40141992000200003

Recebido: Abril 2012

Primeira Decisão: Maio 2012 Aceito: Junho 2012 